\title{
Systematic analysis of the interplay between synthesis route, microstructure and thermoelectric performance in p-type $\mathbf{M g}_{2} \mathbf{S i}_{0.2} \mathbf{S n}_{0.8}$
}

\author{
H. Kamila ${ }^{\mathrm{a} *}$, G. K. Goyal ${ }^{\mathrm{c} *}$, A. Sankhla ${ }^{\mathrm{a}}$, P. Ponnusamy ${ }^{\mathrm{a}}$, E. Mueller ${ }^{\mathrm{a}, \mathrm{b}}$, T. Dasgupta ${ }^{\mathrm{c}}$ and J. de Boor $^{\mathrm{a}}$ \\ ${ }^{\text {a }}$ Institute of Materials Research, German Aerospace Center (DLR), 51147 Koeln, Germany \\ ${ }^{\mathrm{b}}$ Institute of Inorganic and Analytical Chemistry, Justus Liebig University Giessen, 35392 Giessen, Germany \\ ${ }^{c}$ Department of Metallurgical Engineering and Materials Science, Indian Institute of Technology Bombay,
} Mumbai 400 076, India

Corresponding Authors: hasbuna.kamila@dlr.de, Johannes.deBoor@dlr.de

\begin{abstract}
For thermoelectric materials, the synthesis route is - besides composition - the crucial factor governing the thermoelectric transport properties and hence the performance of the material. Here we present a systematic analysis of the influence of the synthesis technique on microstructure and thermoelectric transport properties in Li doped $\mathrm{Mg}_{2} \mathrm{Si}_{0.2} \mathrm{Sn}_{0.8}$. The samples were prepared using two wide-spread, but quite different synthesis methods: high energy ball milling and induction melting. Microstructural analysis (scanning electron microscopy, X-ray diffraction) reveals that ball milled samples are more homogenous than induction melted ones, which exhibit some $\mathrm{Si}$-rich $\mathrm{Mg}_{2}(\mathrm{Si}, \mathrm{Sn})$ and $\mathrm{MgO}$ as secondary phases. On a first glance the thermoelectric properties are qualitatively similar with $z T_{\max } \approx 0.4$ for both routes. However, a systematic analysis of the high temperature transport data in the framework of a single parabolic band model points out that the induction melted samples have a systematically reduced mobility and increased lattice thermal conductivity which can be tied to the differences in the microstructure. The reduced mobility can be attributed to a further carrier scattering mechanism for the induction melted samples in addition to the acoustic phonon and alloy scattering that are observed for both synthesis routes while increased lattice thermal conductivity is due to the larger grain size and presence of secondary phases. In consequence this leads to significantly enhanced thermoelectric transport properties for ball milled samples (effective material parameter $\beta$ is $\sim 20 \%$ larger) and a predicted relative difference in device efficiency of more than $10 \%$.
\end{abstract}

Key words: Ball milling; Induction melting; Single Parabolic Band Model; Thermoelectrics; Thermoelectric transport properties analysis 


\section{Introduction}

Thermoelectric materials can directly convert heat into electricity, thus providing an alternative approach for power generation and refrigeration. Thermoelectric generators have numerous advantages such as no moving parts, a long lifespan, and scalability without efficiency losses compared to other energy conversion techniques [1]. Thermoelectric generators are developed for a wide range of applications such as heat engines for military and space applications, automotive, and personal climate-control applications [2]. The performance of thermoelectric materials can be evaluated by the dimensionless figure of merit $z T=\frac{S^{2} \sigma}{\kappa} T$, where $S$ is the Seebeck coefficient, $\sigma$ the electrical conductivity, $\kappa$ the thermal conductivity, and $T$ the temperature. To ensure a satisfactory thermoelectric performance, thermoelectric materials should have a high power factor, $P F=S^{2} \sigma$ and a low thermal conductivity $\kappa$.

Thermoelectric materials with high zT include, among others, nanostructured PbTe [3], $\mathrm{CoSb}_{3}$-based Skutterudites [4], half-Heusler compounds [5, 6], Zintl phases [7] and $\mathrm{Mg}_{2} \mathrm{Si}$ based solid solutions [8]. Thermoelectric materials are synthesized by various synthesis techniques such as melting of the elements followed by slow cooling and long-time annealing [9], multi-step solid-state reaction [10, 11], self-propagating high temperature synthesis [12, 13], mechanical alloying [14, 15], induction melting [16-18], spark plasma sintering [19], melt-spinning, or combinations of these techniques followed by a compaction process [20, 21]. The synthesis route affects the thermoelectric performance of a material in a complex fashion: temperature can govern carrier concentration through dopant solubility or temperature dependent loss mechanisms (evaporation, oxidation, precipitation); carrier mobility and lattice thermal conductivity are strongly influenced by the microstructure of the sample. Furthermore different synthesis routes can result in various amounts and distributions of secondary phases which will also affect the thermoelectric transport properties. For an optimization of thermoelectric materials an evaluation of different synthesis approaches and a method to do so systematically are therefore highly desirable.

Among several thermoelectric materials, magnesium silicide based solid solutions are highly promising for thermoelectric applications in the middle temperature range (300-800 K) due to materials abundance, non-toxicity, low density and cost, good environmental compatibility, and high thermoelectric performance for n-type $(z T \approx 1.4)[8,14,22-24]$. Compared to $n$ type $\mathrm{Mg}_{2}(\mathrm{Si}, \mathrm{Sn})$, p-type $\mathrm{Mg}_{2}(\mathrm{Si}, \mathrm{Sn})$ has inferior properties $\left(z T_{\text {max }} \approx 0.6\right)$ and further 
optimization is highly desirable for a practical implementation of $\mathrm{Mg}_{2} \mathrm{Si}$-based thermoelectric generators [25-32]. Both p- and n-type $\mathrm{Mg}_{2}(\mathrm{Si}, \mathrm{Sn})$ are synthesized using different synthesis techniques including high energy ball milling (BM) [14, 32], or melt spinning combined with (spark plasma) sintering [25, 26, 29, 30, 33, 34].

As for basically all material systems, an influence of synthesis technique on mobility $\mu$ and lattice thermal conductivity $\kappa_{L}$ is observed for $\mathrm{Mg}_{2}(\mathrm{Si}, \mathrm{Sn})[25,31,35]$. The potentially rich microstructure due to an incomplete inter-solubility of the binaries $\mathrm{Mg}_{2} \mathrm{Si}, \mathrm{Mg}_{2} \mathrm{Sn}$ (and $\left.\mathrm{Mg}_{2} \mathrm{Ge}\right)[36,37]$ is particular to this material system; furthermore the possible influence of defects [38] and Mg-based secondary phases due to the volatility of $\mathrm{Mg}$ and its sensitivity to oxidation [39].

The synthesis that yields the best thermoelectric properties cannot be identified from the comparison of experimental data only, in particular not from different publications: First, the sensitivity of $z T(n)$ might occlude the effect of synthesis route on fundamental transport parameters and secondly there is significant uncertainty in the experimental thermoelectric transport data, which can easily lead to measurement uncertainties of $>20 \%$ for $z T$ [40, 41]. Thus, for a meaningful comparison of synthesis techniques, measurement of the transport properties using the same set of equipment is desired, a model-based approach is required as well as the extraction and comparison of more fundamental material parameters that are not affected by carrier concentration variation.

Using the well-established single parabolic band (SPB) model, we have systematically investigated the differences of Li-doped $\mathrm{Mg}_{2} \mathrm{Si}_{0.2} \mathrm{Sn}_{0.8}$ fabricated by two popular synthesis routes: high energy ball milling (BM) and induction melting (IM) [14, 18, 42]. The composition was chosen because $\mathrm{Li}$ is the most efficient dopant for p-type $\mathrm{Mg}_{2} \mathrm{Si}_{1-x} \mathrm{Sn}_{x}$ and the samples with $x=0.8$ have similar efficiency as the samples with $x=0.6$ but a higher power factor [32, 43]; they are also further outside the reported miscibility gap which is important for long term stability [44-46]. Generally, for both n- and p-type $\mathrm{Mg}_{2}(\mathrm{Si}, \mathrm{Sn})$ relatively large differences in performance are reported from different experimental studies [30,43] making this class a suitable candidate for a systematic comparison of synthesis techniques.

In this study, we show that both IM and BM can be used to obtain p-type $\mathrm{Mg}_{2} \mathrm{Si}_{0.2} \mathrm{Sn}_{0.8}$ samples which show qualitatively similar thermoelectric properties. However, analysis of the transport data in the framework of the SPB model reveals distinct differences in the mobility parameter $\mu_{0}$ and the lattice thermal conductivity $\kappa_{L}$. This results in a higher effective material 
parameter $\beta$ for the $\mathrm{BM}$ samples and hence superior thermoelectric properties compared to induction melting. We can show that the differences in carrier mobility are related to differences of the carrier scattering and that both the differences in $\mu_{0}$ and $\kappa_{L}$ can be attributed to differences in the microstructure of the samples. Thus, exemplarily for that material system, we demonstrate how the influence of synthesis route on the thermoelectric properties can be well understood and quantified using a SPB model.

\section{Materials and methods}

P-type $\mathrm{Mg}_{2} \mathrm{Si}_{0.2} \mathrm{Sn}_{0.8}$ samples were synthesized using two different synthesis methods: high energy ball milling and induction melting, both followed by current assisted sintering. The detailed procedure of the BM synthesis is described in a previous report [42]. The precursors were milled for 4 hours under Ar atmosphere and sintered using current assisted sintering at $923 \mathrm{~K}$ for 10 minutes. The $\mathrm{Li}$ concentration in $\mathrm{Mg}_{2-\mathrm{y}} \mathrm{Li}_{\mathrm{y}} \mathrm{Si}_{0.2} \mathrm{Sn}_{0.8}$ was chosen as $y=$ $0.01,0.02$, and 0.03 .

For induction melted samples, magnesium granules 99.8\% (SRL), silicon pieces 6N (Alfa Aesar), tin ingots 99.5\% (Merck) and lithium carbonate powder 99\% (Lobachemie)) were used as precursors. The $\mathrm{Li}_{2} \mathrm{CO}_{3}$ powder and $\mathrm{Mg}$ coarse powder (excess $\mathrm{Mg}$ (5 wt $\%$ ) was added to compensate for the $\mathrm{Mg}$ loss during melting) were mixed, cold compacted and kept with the other precursor elements in a graphite crucible which was covered with a lid and is kept under mechanical pressure applied from a piston rod to suppress the Mg loss in the system. The reaction chamber was evacuated and back-filled with Argon at $0.5 \mathrm{~atm}$. The crucible was heated to $1253 \mathrm{~K}$ in 6 minutes and kept at this temperature for 5 minutes. During the process, all the reactants are melted and solidified ingots were formed during cooling. The ingots were hand-crushed using an agate mortar and pestle. The powder obtained was sintered in a uni-axial induction-assisted hot press in Ar atmosphere at 923-938 $\mathrm{K}$ (range of temperature fluctuation), a holding time of 5 minutes and a pressure of $55 \mathrm{MPa}$. The $\mathrm{Li}$ concentration in $\mathrm{Mg}_{2.1-y} \mathrm{Li}_{y} \mathrm{Si}_{0.2} \mathrm{Sn}_{0.8}$ was varied with $y=0.02,0.03$, and 0.04 . These slightly different parameters have been used as each route has been optimized separately before. Phase formation in the obtained pellets were characterized using a Philips PANalytical XRD system at IITB. The microstructure and phase purity of the samples were observed by using a Zeiss Ultra 55 at IITB. Moreover the functional homogeneity of the samples was characterized by a spatial mapping of the Seebeck coefficient at room temperature using a Potential \& Seebeck microprobe (PSM) at DLR [47, 48]. 
The temperature dependent measurements of Seebeck coefficient and electrical conductivity were performed using an in-house developed facility with a four-probe technique $[49,50]$. The thermal diffusivity $(\alpha)$ of the pellets was obtained using a Netzsch LFA 427 apparatus. All measurements of $S, \sigma$ and $\alpha$ were performed under Ar and He at 300-680 K. The thermal conductivity $(\kappa)$ was calculated using the relation $\kappa=\rho C_{p} \alpha$, where $\rho$ and $C_{p}$ are sample density and heat capacity of composition at constant pressure, respectively. The $C_{p}$ value was obtained from the Dulong Petit limit $C_{V}^{\mathrm{DP}}: C_{p}=C_{V}^{\mathrm{DP}}+\frac{9 E_{t}^{2} T}{\beta_{T} \rho}$ where $E_{t} \sim 1.7 \times 10^{-5} \mathrm{~K}^{-1}$ and $\beta_{T} \sim 2.2 \times 10^{-11} \mathrm{~Pa}$, are the linear coefficient of thermal expansion and an isothermal compressibility, respectively [51,52]. In the relevant temperature range the $C_{p}$ increases from $0.513 \mathrm{~J} / \mathrm{gK}$ to $0.527 \mathrm{~J} / \mathrm{gK}$. The Hall carrier concentration $p_{\mathrm{H}}$ was calculated from the Hall coefficient $\left(R_{\mathrm{H}}\right)$ assuming a single carrier type using $p_{\mathrm{H}}=\frac{1}{R_{\mathrm{H}} e}$, where $e$ is the electronic charge. The room temperature $R_{\mathrm{H}}$ for different samples was determined using an in-house facility with a van der Pauw configuration under varying magnetic field of maximum $0.5 \mathrm{~T}$ $[51,53]$. The main aim of the manuscript is to compare two different synthesis techniques and to draw conclusions from the observed differences. Therefore all thermoelectric properties measurements, including Hall measurements, were conducted, each, using the same of facilities at DLR. For that reason measurement precision (related to reproducibility) is more relevant in the following than measurement accuracy (closeness of the measurement to the true value). Based on periodic reference measurements precision is specified as $\pm 2 \%, \pm 5 \%, \pm 5 \%$ and $\pm 10 \%$ for $S, \sigma, \kappa$ and $R_{\mathrm{H}}$ (and shown as error bars in the following), while measurement accuracy is given by $\pm 5 \%, \pm 5 \%, \pm 8 \%$ and $\pm 10 \%$ based on comparison with the NIST standard reference material 3451 and international round robin tests [41, 54, $55]$. 


\section{Results}

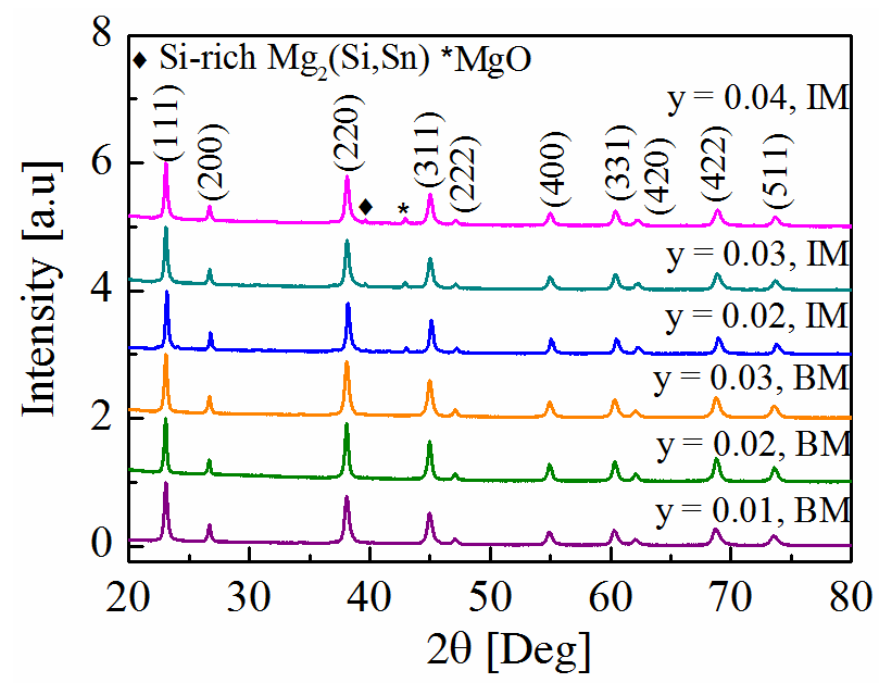

Figure 1 XRD patterns of ball milled p-type $\mathrm{Mg}_{2-y} \mathrm{Li}_{y} \mathrm{Si}_{0.2} \mathrm{Sn}_{0.8}$ samples with $\boldsymbol{y}=\mathbf{0 . 0 1 , 0 . 0 2}$ and $\mathbf{0 . 0 3}$ and corresponding patterns of induction melted samples with $\boldsymbol{y}=\mathbf{0 . 0 2 , 0 . 0 3}$ and $\mathbf{0 . 0 4}$.

Figure 1 shows the XRD patterns of p-type $\mathrm{Mg}_{2} \mathrm{Si}_{0.2} \mathrm{Sn}_{0.8}$ compositions prepared by ball milling and induction melting. The main peaks can be indexed to cubic anti-flourite crystal structure with space group $F m \overline{3} m$. The XRD data indicates the BM samples to be phase pure, while some impurity peaks corresponding to $\mathrm{MgO}$ and $\mathrm{Si}$-rich $\mathrm{Mg}_{2}(\mathrm{Si}, \mathrm{Sn})$ are observed for the IM samples (impurity peak positions are indicated in Figure 1). The Fullprof software was employed to calculate the lattice parameter using Rietveld refinement for all the samples. The refinement results are given in Table 1 . The weight fraction of the secondary $\mathrm{MgO}$ phase (for IM samples) was also estimated and given in Table 1. At room temperature the lattice parameters of the p-type $\mathrm{Mg}_{2} \mathrm{Si}_{0.2} \mathrm{Sn}_{0.8}$ samples varied between $a=6.664-6.690 \AA$ in range with previous reports [56-58]. Such significant variation in the lattice parameters for similar nominal compositions can be attributed to minimal differences in the $\mathrm{Si}: \mathrm{Sn}$ ratio. The BM samples have a lower scatter in the lattice parameter (standard deviation of 0.003) compared to the IM samples (0.008) indicative of the ball milling method resulting in a better reproducibility. While the refinement shows some differences in $\mathrm{Si}: \mathrm{Sn}$ ratio between the samples, and this parameter in principle clearly influences the thermoelectric performance [32], the estimated change of properties due to the measured change in $\mathrm{Si}: \mathrm{Sn}$ ratio is small compared to the experimental precision and therefore neglected in the following. Note that lattice parameter and $\mathrm{Si}: \mathrm{Sn}$ ratio have been refined independently of each other. 
Table 1: Results of refinement of XRD data for BM samples and IM samples

\begin{tabular}{|l|c|c|c|c|c|}
\hline Nominal composition & Method & Lattice parameter a ( & $\begin{array}{c}\mathrm{Si}(\text { at. } \\
\%)\end{array}$ & $\begin{array}{c}\text { Sn } \\
\text { (at. \%) }\end{array}$ & $\mathrm{MgO}$ (wt \%) \\
\hline $\mathrm{Mg}_{1.99} \mathrm{Li}_{0.01} \mathrm{Si}_{0.2} \mathrm{Sn}_{0.8}$ & $\mathrm{BM}$ & $6.690(1)$ & 0.18 & 0.82 & - \\
\hline $\mathrm{Mg}_{1.98} \mathrm{Li}_{0.02} \mathrm{Si}_{0.2} \mathrm{Sn}_{0.8}$ & $\mathrm{BM}$ & $6.683(1)$ & 0.193 & 0.807 & - \\
\hline $\mathrm{Mg}_{1.97} \mathrm{Li}_{0.03} \mathrm{Si}_{0.2} \mathrm{Sn}_{0.8}$ & $\mathrm{BM}$ & $6.687(1)$ & 0.188 & 0.812 & - \\
\hline $\mathrm{Mg}_{2.08} \mathrm{Li}_{0.02} \mathrm{Si}_{0.2} \mathrm{Sn}_{0.8}$ & $\mathrm{IM}$ & $6.671(1)$ & 0.18 & 0.82 & $6.64(0.19)$ \\
\hline $\mathrm{Mg}_{2.07} \mathrm{Li}_{0.03} \mathrm{Si}_{0.2} \mathrm{Sn}_{0.8}$ & $\mathrm{IM}$ & $6.664(1)$ & 0.20 & 0.80 & $9.37(0.19)$ \\
\hline $\mathrm{Mg}_{2.06} \mathrm{Li}_{0.04} \mathrm{Si}_{0.2} \mathrm{Sn}_{0.8}$ & $\mathrm{IM}$ & $6.680(1)$ & 0.17 & 0.83 & $7.37(0.17)$ \\
\hline
\end{tabular}

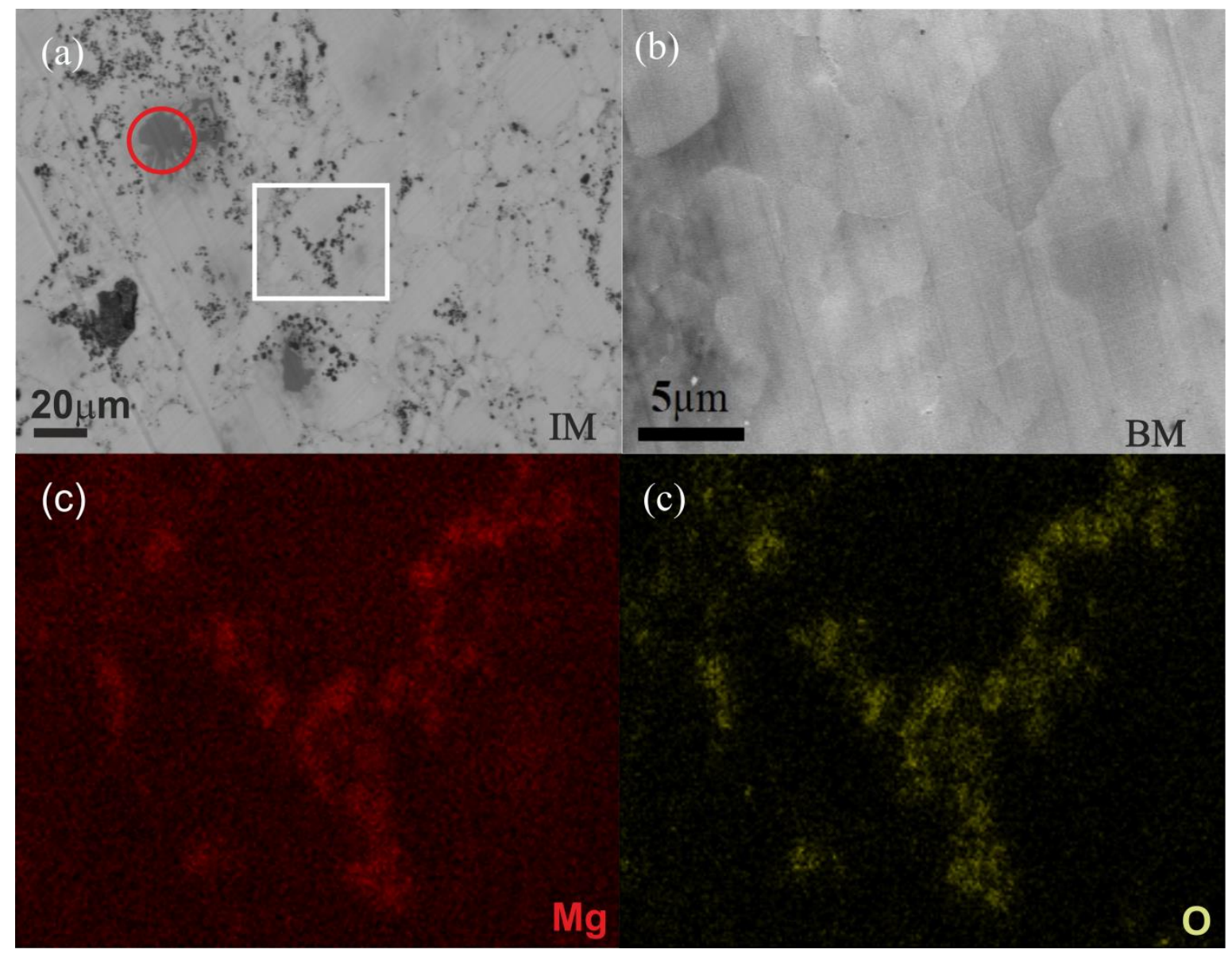

Figure 2 SEM image of (a) IM sample $(\boldsymbol{y}=\mathbf{0 . 0 2})$, (b) BM sample $(y=0.02)$, and (c) EDS mapping of the white rectangle marked in (a) indicating formation of $\mathrm{MgO}$ during IM synthesis.

Microstructure and phase purity of the obtained pellets were characterized utilizing SEM in back scatter electron mode. Differences in average grain size and phase homogeneity of the samples are observed. The grain size is estimated using ImageJ software after measuring over 100 grains in an image for averaging; for the BM sample it is estimated to be $\sim 5 \mu \mathrm{m}$ which is in agreement with previous publications on samples with similar compositions synthesized 
using the same setup $[14,45]$; for the IM sample the average grain size is $\sim 23 \mu \mathrm{m}$. The larger grain size of the IM samples compared to the BM samples is presumably due to the differences in the crushing process of the different synthesis routes. The IM samples were hand-crushed after the melting process whereas the BM samples were milled under a much higher mechanical energy than hand crushing provides, this results in a much smaller grain size. The BM sample (Figure 2b) is also more homogenous than the IM sample (Figure 2a) as observed from the contrast (grey areas) in the back-scattered SEM image and EDS mapping (see supplementary Figure S2). The contrast appears due to variation of the local $\mathrm{Si} / \mathrm{Sn}$ distribution [45]. Additionally, black patches are observed in the SEM image (mainly the IM sample). These regions are located both within the grains and along grain boundaries and have been identified as $\mathrm{MgO}$ by elemental analysis. Elemental mapping was also carried out in select areas (indicated by the white square in Figure 2a) containig the black patches (shown in Figure 2c) which confirms the presence of $\mathrm{MgO}$. Here, the EDX mapping shows a higher count for $\mathrm{Mg}$ than the in the surrounding $\mathrm{Mg}_{2}(\mathrm{Si}, \mathrm{Sn})$ matrix which is in line with the higher atomic density of $\mathrm{Mg}$ in $\mathrm{MgO}$ compared to that in the $\mathrm{Mg}_{2} \mathrm{Si}_{1-x} \mathrm{Sn}_{x}$ phase. The formation enthalpy of $\mathrm{MgO}$ is $603 \mathrm{~kJ} / \mathrm{mol}$ at $300 \mathrm{~K}$ [59] and it is presumably formed during the melting process. The greyish area (indicated by a red circle) shows $\mathrm{Si}$-rich $\mathrm{Mg}_{2}(\mathrm{Si}, \mathrm{Sn})$ regions with silicon to tin molar ratio of $(\mathrm{Si}: \mathrm{Sn}) \approx 80: 20$ mole $\%$ (Figure $2 \mathrm{a}$ ).
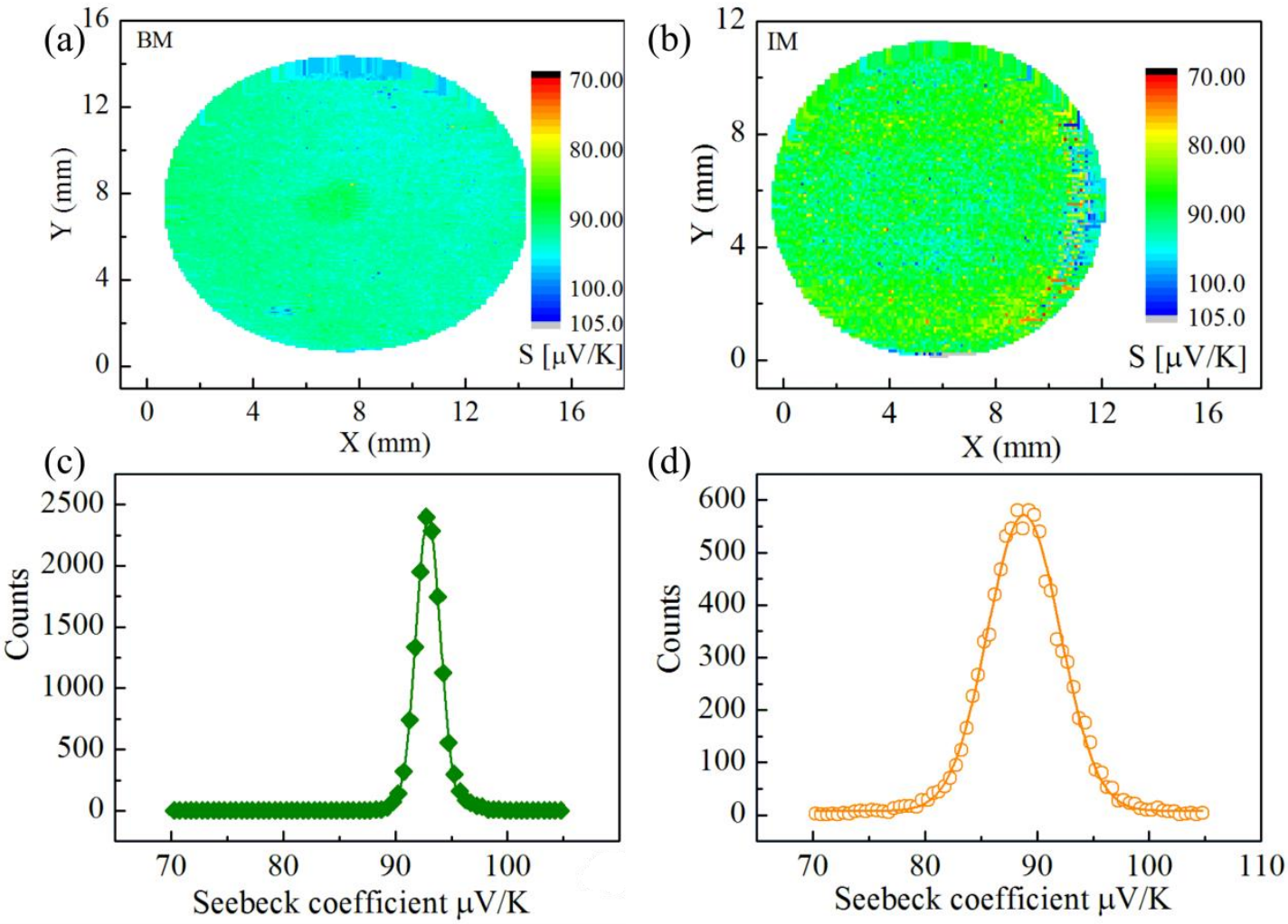
Figure 3 (a) Spatial Seebeck mapping of ball milled sample for $\boldsymbol{y}=\mathbf{0 . 0 2}$ with frequency distribution in (c) and (b) induction melted sample for $\boldsymbol{y}=\mathbf{0 . 0 4}$ with frequency distribution in (d) at room temperature.

The functional homogeneity and dominant carrier type of BM and IM samples are studied by spatial mapping of the Seebeck coefficient. Figure 3 illustrates the functional homogeneity of the BM $(y=0.02)$ and IM $(y=0.04)$ samples. For the analysis of the IM sample, we excluded a few outlier with close to zero Seebeck values. The absolute Seebeck coefficient for BM samples $(S=88.8 \mu \mathrm{V} / \mathrm{K})$ and IM samples $(S=92.9 \mu \mathrm{V} / \mathrm{K})$ from PSM match well with the obtained Seebeck measurement data at room temperature from the temperature-dependent measurements. The functional homogeneity can be quantified by the full width half maximum (FWHM) of the Seebeck coefficient distribution profiles as shown in Figures $3 \mathrm{c}$ and $\mathrm{d}$; the lower the value the better the homogeneity. The FWHM of the BM sample is $2.6 \%$ which is lower than that of the IM sample (7.7\%), indicating that the BM sample is more homogenous than the IM sample. Dopant incorporation and dopant efficiency will generally depend on the $\mathrm{Si}: \mathrm{Sn}$ ratio. For n-type $\mathrm{Mg}_{2}(\mathrm{Si}, \mathrm{Sn})$ it has been found that the dopant incorporation is favoured for solid solutions with higher Sn content [31] and for p-type dopant efficiency increases as well with increasing Sn content [43]. The higher fluctuation of the local Si:Sn ratio for the IM samples is therefore expected to increase the fluctuation of the measured local Seebeck coefficient even if the microstructural features are not fully resolved.

\section{Thermoelectric properties}

The nominal composition of BM and IM samples together with their corresponding room temperature Hall carrier concentration $\left(p_{\mathrm{H}}\right)$, density of states effective mass $\left(m_{\mathrm{D}}^{*}\right)$, and Hall mobility $\left(\mu_{\mathrm{H}}\right)$ based on the SPB model are listed in Table 2 .

Table 2 Thermoelectric transport data of p-type $\mathrm{Mg}_{2} \mathrm{Si}_{0.2} \mathrm{Sn}_{0.8}$ synthesized by using ball milling and induction melting methods based on the SPB model

\begin{tabular}{|l|c|c|c|c|c|}
\hline Composition & Li content $y$ & $\begin{array}{l}\text { synthesis } \\
\text { methods }\end{array}$ & $\begin{array}{c}p_{\mathrm{H}} \times 10^{20} \\
\left(\mathrm{~cm}^{-3}\right)\end{array}$ & $m_{\mathrm{D}}^{*}\left(\mathrm{~m}_{0}\right)$ & $\mu_{\mathrm{H}}\left(\mathrm{cm}^{2} / \mathrm{Vs}\right)$ \\
\hline $\mathrm{Mg}_{1.99} \mathrm{Li}_{0.01} \mathrm{Si}_{0.2} \mathrm{Sn}_{0.8}$ & 0.01 & $\mathrm{BM}$ & 1.0 & 1.40 & 45 \\
\hline $\mathrm{Mg}_{1.98} \mathrm{Li}_{0.02} \mathrm{Si}_{0.2} \mathrm{Sn}_{0.8}$ & 0.02 & $\mathrm{BM}$ & 1.3 & 1.17 & 49 \\
\hline $\mathrm{Mg}_{1.97} \mathrm{Li}_{0.03} \mathrm{Si}_{0.2} \mathrm{Sn}_{0.8}$ & 0.03 & $\mathrm{BM}$ & 1.8 & 1.26 & 42 \\
\hline $\mathrm{Mg}_{2.1-1-1} \mathrm{Li}_{0.02} \mathrm{Si}_{0.2} \mathrm{Sn}_{0.8}$ & 0.02 & $\mathrm{IM}$ & 1.2 & 1.18 & 42 \\
\hline $\mathrm{Mg}_{2.1-\mathrm{y}} \mathrm{Li}_{0.03} \mathrm{Si}_{0.2} \mathrm{Sn}_{0.8}$ & 0.03 & $\mathrm{IM}$ & 1.4 & 1.22 & 37 \\
\hline $\mathrm{Mg}_{2.1-1-\mathrm{Li}} \mathrm{Li}_{0.04} \mathrm{Si}_{0.2} \mathrm{Sn}_{0.8}$ & 0.04 & $\mathrm{IM}$ & 1.6 & 1.22 & 37 \\
\hline
\end{tabular}



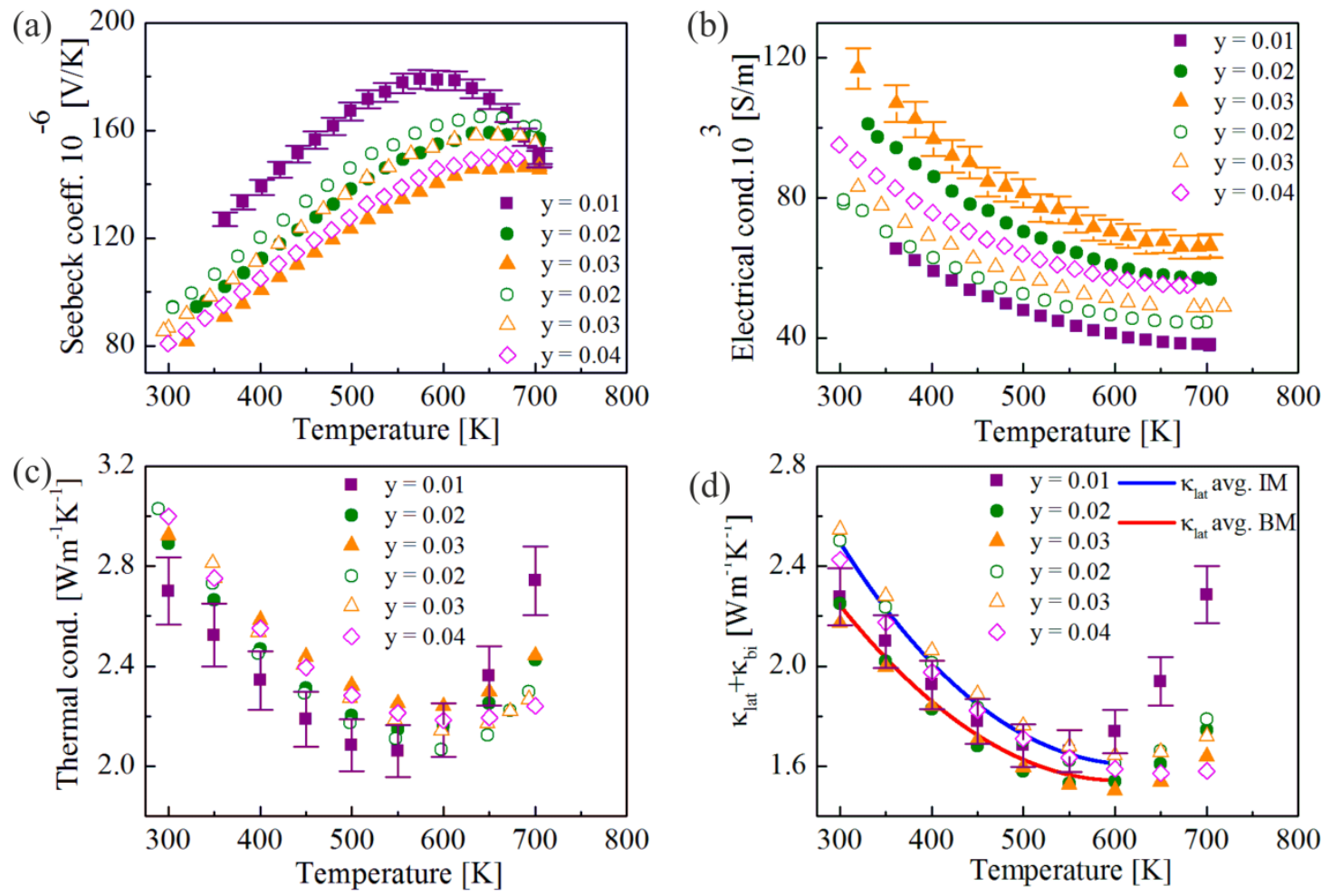

(d)
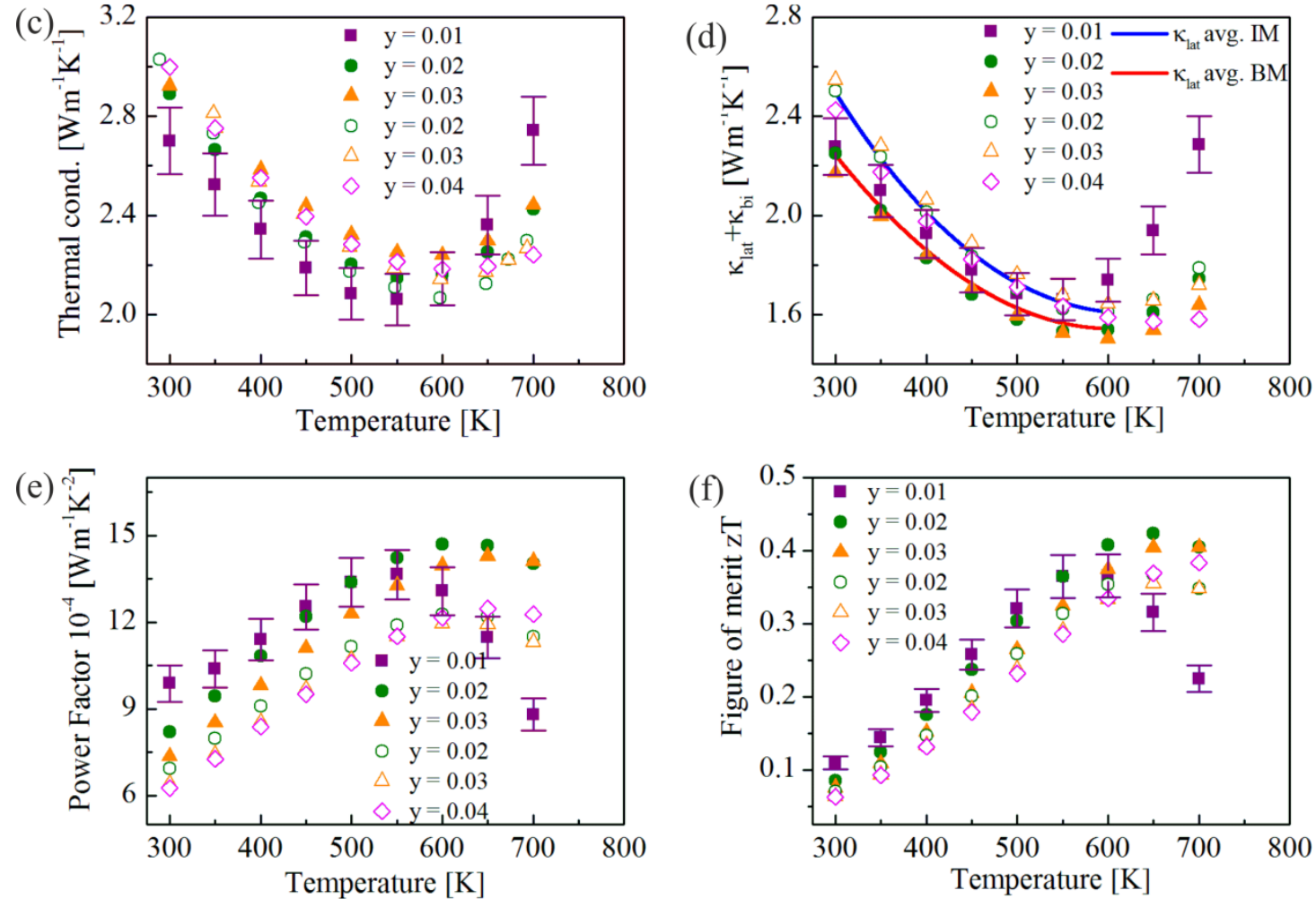

Figure 4. Temperature dependence of (a) Seebeck coefficient, (b) electrical conductivity, (c) thermal conductivity, (d) lattice thermal conductivity, (e) power factor and (f) figure of merit $\boldsymbol{z T}$ of p-type $\mathrm{Mg}_{2} \mathrm{Si}_{0.2} \mathrm{Sn}_{0.8}$ prepared using ball milling (filled symbols) and induction melting (empty symbols).

The temperature dependent TE properties of the BM and IM samples are plotted in Figure 4a. All samples exhibit positive Seebeck coefficient values which indicate p-type conduction. The Seebeck coefficient decreases with increase of the $\mathrm{Li}$ concentration for both BM and IM samples. The Seebeck coefficient starts to bend at lower temperatures for the sample with the lowest carrier concentration $(y=0.01)$ due to an earlier onset of the mixed conduction regime. The electrical conductivity for all the samples increases with an increase in the $\mathrm{Li}$ concentration. Overall, the electrical conductivity of BM samples is higher than for the IM samples. The thermal conductivity of BM samples increases slightly with higher Li content. The values of the lattice thermal conductivity of the IM samples are larger than those of the 
BM samples at $300-450 \mathrm{~K}$. The maximum power factor $P F_{\max }=1.5 \mathrm{mWm}^{-1} \mathrm{~K}^{-2}$ is achieved at $600 \mathrm{~K}$ for the BM sample with $y=0.02$ while for the IM samples the power factor is generally lower $\left(P F_{\max }=1.2 \mathrm{mWm}^{-1} \mathrm{~K}^{-2}\right)$. The BM sample with $y=0.02$ has the highest $P F$ and the lowest thermal conductivity which lead to an optimum figure of merit $(z T)$ of around $0.42 \pm 0.03$ at $650 \mathrm{~K}$. In the case of IM samples, the optimum $z T$ is achieved as $0.38 \pm 0.03$ at $700 \mathrm{~K}$ for $y=0.04$, partially because of a better suppression of the bipolar contribution. In general, the thermoelectric properties of BM and IM samples are qualitatively similar.
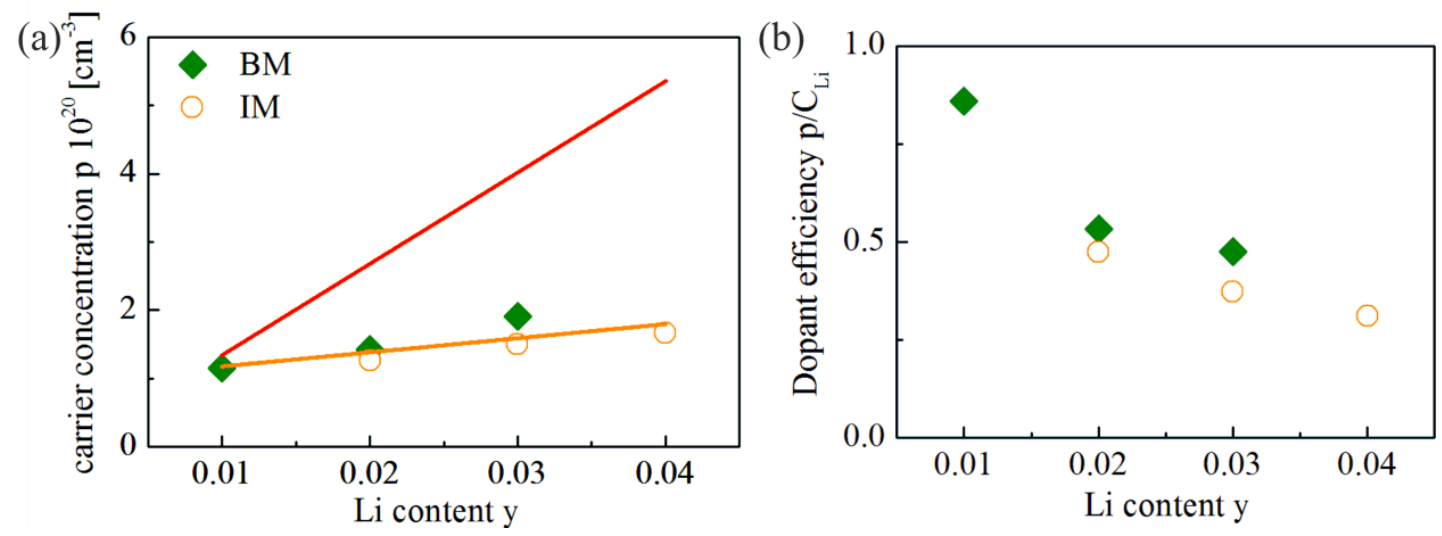

Figure 5. (a) The obtained carrier concentration changes subproportional and (b) dopant efficiency decreases with higher Li content.

The carrier concentration $(p)$ of BM samples is slightly higher than that of IM samples (see Table 2) for the same nominal Li content. The obtained carrier concentration increases subproportional $\left(p_{\mathrm{H}}=1-1.8 \times 10^{20} \mathrm{~cm}^{-3}\right)$ with higher Li content for both sample types and is slightly steeper for BM samples. Thus the Seebeck coefficient reduces with increase in Li concentration (see Figure 4a). The relations between the carrier concentration and dopant efficiency vs. Li content are illustrated in Figure 5a and b. The theoretical limit (red line) is calculated for a lattice constant of $a=6.8 \times 10^{-10} \mathrm{~m}$ and under the assumption that each $\mathrm{Li}$ atom replaces one $\mathrm{Mg}$ atom and provides one free hole. Figure 5a shows that the obtained carrier concentrations of both BM and IM samples are far below the theoretical limits for higher Li content (see also Table 2), which is observed consistently in literatures [25, 27, 29, 30] and might be related to defect formation in the material [25]. Moreover, the dopant efficiency (obtained carrier concentration over theoretical limit) is slightly higher for BM samples but reduces with higher Li content for both kinds of samples. 


\section{Discussion}

From the results of XRD and SEM it is clear that the synthesis method (BM vs. IM) affects the microstructure (Figure 2). The difference in the microstructure is possibly due to the reaction mechanism of the methods. For the BM route it was shown in a previous report that $\mathrm{Mg}_{2} \mathrm{Sn}$ is formed in the beginning of the reaction and $\mathrm{Si}$ diffuses into the system during milling [14], resulting in a multi-phase material with neighboring compositions at the end of the milling stage. The single-phase $\mathrm{p}-\mathrm{Mg}_{2} \mathrm{Si}_{0.2} \mathrm{Sn}_{0.8}$ is formed during the compaction. On the other hand, IM p- $\mathrm{Mg}_{2} \mathrm{Si}_{0.2} \mathrm{Sn}_{0.8}$ is formed during the melting process. The precursors and the melted samples were possibly oxidized during the melting process and the preparation under ambient condition. As a result, the secondary phases $\left(\mathrm{MgO}\right.$ and $\mathrm{Si}$-rich $\left.\mathrm{Mg}_{2}(\mathrm{Si}, \mathrm{Sn})\right)$ are more clearly observed for the IM sample (see Figure 2). We also note that the $\mathrm{MgO}$ distribution is different to a previous report on $\mathrm{Mg}_{2} \mathrm{Si}$ where $\mathrm{MgO}$ is found homogenously distributed at the grain boundaries [35], in contrast the present study. This indicates that the synthesis steps and the change in composition $\left(\mathrm{Mg}_{2}(\mathrm{Si}, \mathrm{Sn})\right.$ solid solution in this case [25]) could affect the distribution of $\mathrm{MgO}$. Also, $\mathrm{MgO}$ was possibly formed due to the use of $\mathrm{Li}_{2} \mathrm{CO}_{3}$ as $\mathrm{Li}$ source [25]. However the amount of $\mathrm{MgO}$ obtained from the refinement results $(\mathrm{MgO}=6.64,9.37$ and $7.37 \mathrm{wt} \%$ ) indicate that the $\mathrm{MgO}$ does not depend entirely on the $\mathrm{Li}_{2} \mathrm{CO}_{3}$ concentrations used [59]. The formation of Si-rich $\mathrm{Mg}_{2}(\mathrm{Si}, \mathrm{Sn})$ phase at lower temperature $(<973 \mathrm{~K})$ is possibly due to boundaries of the miscibility gap of the composition [60].

The differences in microstructure and secondary phases give some indications for the origin of different TE properties of BM and IM samples. In particular, the presence of $\mathrm{MgO}$ can degrade the electrical properties of $\mathrm{Mg}_{2}(\mathrm{Si}, \mathrm{Sn})$ [25, 35]; we also observe that the electrical conductivity of BM samples is higher than that of IM samples. Note that the electrical conductivity of the IM samples monotonically decreases with increase in temperature in contrast to the previous report for the highest $\mathrm{MgO}$ content [35], even though all $\mathrm{MgO}$ contents are higher in the present case. Moreover, the presence of $\mathrm{Si}$-rich $\mathrm{Mg}_{2}(\mathrm{Si}, \mathrm{Sn})$ phases presumably contributes to the reduction of the electrical conductivity.

For a deeper analysis, a single parabolic band (SPB) model is utilized to understand the influence of synthesis techniques (BM and IM) on the TE properties and to identify a superior synthesis technique. The relevant equations are:

$S=\frac{k_{B}}{e}\left(\frac{2 F_{1}(\eta)}{F_{0}(\eta)}-\eta\right)$ 
$p=4 \pi\left(\frac{2 m_{D}^{*} k_{B} T}{h^{2}}\right)^{1.5} F_{\frac{1}{2}}(\eta)$

$p_{\mathrm{H}}=\frac{p}{r_{H}}, r_{\mathrm{H}}=\frac{1.5 F_{0.5}(\eta)(0.5) F_{-0.5}(\eta)}{F_{0}^{2}(\eta)}$

$\mu_{\mathrm{H}}=\mu_{0} \frac{F_{-0.5}(\eta)}{2 F_{0}(\eta)}$

Here $e$ is the elementary charge, $k_{B}$ is Boltzmann's constant, $F_{i}(\eta)$ the Fermi integral of order $i F_{i}=\int_{0}^{\infty} \frac{\epsilon^{i} d \epsilon}{1+\operatorname{Exp}[\epsilon-\eta]}$, and $\eta$ is the reduced chemical potential which is given by $\eta=$ $\frac{E_{\mathrm{F}}}{k_{B} T}$, where $E_{\mathrm{F}}$ is the Fermi energy. For the calculation, we have assumed a scattering parameter $(\lambda=0)$ corresponding to the energy dependence of scattering on acoustic phonons (AP) and alloy scattering (AS) [6, 61-63]. The true carrier concentration $(p)$ is calculated from experimental Hall carrier concentration $\left(p_{\mathrm{H}}\right)$ using the Hall factor $\left(r_{\mathrm{H}}\right)$.

The density of states effective masses of both BM and IM samples are calculated using Eq. 2 . The values are similar $m_{\mathrm{D}}^{*} \approx 1.2 m_{0}$ except for $y=0.01$ of $\mathrm{BM}$ sample (Table 1 ). This confirms that the density of states effective mass is independent of the synthesis techniques. However, the Hall mobility is slightly higher for BM samples (see Table 2). The Hall mobility of the ball milled sample with $y=0.01$ was calculated by extrapolating the electrical conductivity data to room temperature using a SPB model. As the measured Hall mobility is affected by the sample carrier concentration, we use the mobility parameter $\mu_{0}$ for a comparison between the synthesis techniques instead. This is calculated from the Hall mobility using Eq. 4 and shown in Figure 6a. While the results for the individual samples show some scatter, it can be seen that the BM samples on average exhibit a higher mobility parameter. 

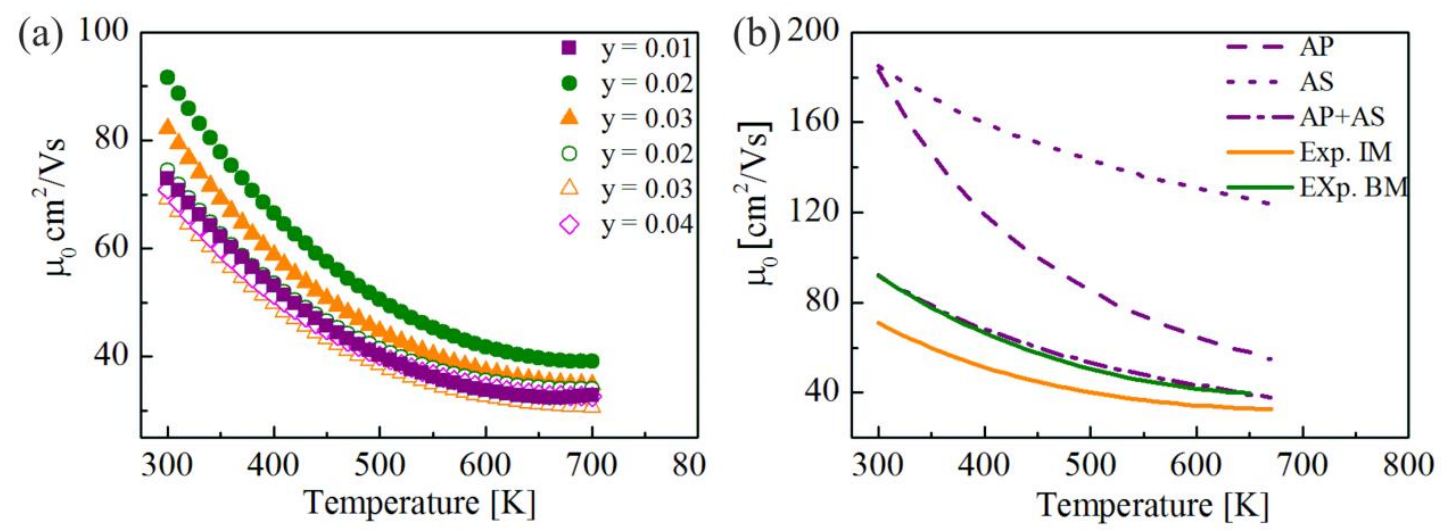

Figure 6 (a) Mobility parameter of BM (filled symbols) and IM (empty symbols) samples and (b) Mobility parameter of a BM sample $(\boldsymbol{y}=\mathbf{0 . 0 2})$ and an IM sample $(\boldsymbol{y}=\mathbf{0 . 0 4})$ (solid lines, directly from experimental data ) and predicted mobility parameters taking acoustic phonon scattering (dashed lines) and alloy scattering (dotted lines) as well as the combination of both (dashed-dotted lines) into account.

We have shown that the whole solid solution range of $\mathrm{p}-\mathrm{Mg}_{2} \mathrm{Si}_{1-x} \mathrm{Sn}_{x}$ with $x=0-1$ and in particular the electrical conductivity can be modelled using a SPB model taking acoustic phonon (AP) scattering and alloy scattering (AS) into account as scattering mechanisms [32]. Here we apply the same model specifically to p-type $\mathrm{Mg}_{2} \mathrm{Si}_{0.2} \mathrm{Sn}_{0.8}$ prepared with different synthesis techniques to check for differences in carrier scattering. The mobility parameter $\mu_{0}$ is calculated using Matthiessen's rule [10]:

$$
\frac{1}{\mu_{0}}=\frac{1}{\mu_{0}^{A P}}+\frac{1}{\mu_{0}^{A S}}
$$

Acoustic phonon scattering mobility $\left(\mu_{0}^{A P}\right)$ is described by the following equation $[10,63]$ :

$$
\mu_{0}^{A P}=\frac{\pi \sqrt{8} e \hbar^{4} \rho v_{l}^{2}}{4 E_{\mathrm{Def}^{2}}{ }^{2}\left(m_{S}\right)^{2.5}\left(k_{B} T\right)^{1.5}}
$$

$\hbar$ is the reduced Planck constant, $k_{B}$ is Boltzmann's constant, $\rho$ is the theoretical mass density, $v_{l}$ is the longitudinal velocity of sound $v_{l}=5376 \mathrm{~m}^{2} / \mathrm{s}$ [32], $E_{\text {Def }}$ is the deformation potential which characterizes the interaction between charge carriers and phonons. The single valley effective mass $\left(m_{s}\right)$ is calculated via $m_{s}=m_{\mathrm{D}}^{*} / N_{\mathrm{v}}{ }^{2 / 3}, N_{\mathrm{v}}=2$. Furthermore, the mobility due to alloy scattering is described by $[10,61]$ :

$$
\mu_{0}^{A S}=\frac{16 e \hbar^{4} N_{0}}{3(2)^{1.5} \pi x(1-x) E_{A S}^{2}\left(m_{S}\right)^{2.5}\left(k_{B} T\right)^{0.5}}
$$

$N_{0}$ is the number of atoms per unit volume and $x$ is the $\mathrm{Sn}$ fraction, respectively; $E_{\mathrm{AS}}$ is the alloy scattering potential. We have kept $E_{\text {Def }}=$ const $=9 \mathrm{eV}$ and $E_{\mathrm{AS}}=$ const $=0.5 \mathrm{eV}$ as mentioned in the previous report [32]. Figure $6 \mathrm{~b}$ demonstrates that the AP mobility (dashed 
lines) is more relevant at high temperatures $\mu_{0}^{\mathrm{AP}} \sim T^{-z}$ with $z>1$ and the AS mobility (dotted lines) is comparable at low temperature $\mu_{0}^{\mathrm{AS}} \sim T^{0}$. While for $\mathrm{BM}$ the modeled data represents the experimental data quite well, there is a large discrepancy for the IM sample. While shown here only for one sample we find this for all IM samples. This means that the mobility of the IM samples cannot be modelled with the same constants as the BM samples indicating a difference in the details of the hole scattering. Both $E_{\mathrm{Def}}$ and $E_{\mathrm{AS}}$ are properties supposed to be independent of synthesis route [61, 63]. Nevertheless we have attempted to fit the experimental data of the IM samples allowing for a higher alloy scattering potential or for a higher deformation potential. While the overall fits (naturally) improve especially for a higher deformation potential constant $\left(E_{\text {Def }}=11 \mathrm{eV}\right)$, the temperature dependence is stronger than that of the experimental data so that there is a discrepancy at high temperatures (see supplementary in Fig. S4). We also note that a lower speed of sound for the IM samples would have effectively the same consequence as an increased deformation potential; further measurements are required to disentangle the differences further. For a higher alloy scattering potential, the fit does not capture the temperature dependence (see supplementary in Figure $\mathrm{S} 3)$, indicating that a different $E_{\mathrm{AS}}$ and $E_{\mathrm{Def}}$ are not the reason for the observed discrepancy.

As $\mathrm{MgO}$ has been reported to reduce the mobility in $\mathrm{Mg}_{2} \mathrm{Si}$ [35] and the IM samples contain a significant amount of $\mathrm{MgO}$ (higher than in [35]) we have tried to model the mobility by adding grain boundary scattering as further scattering mechanism [35, 64]. However, the model does not fit with the experimental data and does not exhibit the right temperature dependence, see supplementary in Figure S5. The main reason is that grain boundary scattering is effective mainly at lower $T$, while we observe here a reduction of the mobility of IM samples over the whole temperature range. This indicates that the observed differences between BM and IM cannot be modelled by adding grain boundary scattering as further scattering mechanism. In an earlier work were grain boundary scattering was found to be effective [35], the $\mathrm{MgO}$ particles were observed at the grain boundaries [35], however in our case, the $\mathrm{MgO}$ particles agglomerate and are not only located at the grain boundaries (Figure 2). Thus the position and distribution of $\mathrm{MgO}$ could be the reason for the different behavior. Further possible scattering mechanisms such as point defect scattering and ionized impurities could be considered based on previous reports $[65,66]$. Point defect scattering mechanism has a scattering parameter $\lambda=0$ [65], which is the same as for acoustic phonon and alloy scattering mechanisms, however it is physically hard to justify as potential defects in $\mathrm{Mg}_{2}(\mathrm{Si}, \mathrm{Sn})$ are usually charged and not neutral [38]. Ionized impurity scattering is known to have a strong temperature dependence (mainly relevant at low temperatures) and can 
therefore also be ruled out as potential reason for the observed difference [66]. In summary, our analysis of the electronic transport data using the SPB model allows us to identify the difference in carrier scattering as the reason for systematically reduced mobility. As we furthermore cannot implement a correct description within the single parabolic band model we conclude that the origin is outside the SPB model and is presumably related to the presence of secondary phases in the IM samples.

The lattice thermal conductivity in Figure $4 \mathrm{~d}$ was obtained from the measured thermal conductivity $\kappa_{\mathrm{lat}}+\kappa_{\mathrm{bi}}=\kappa-\kappa_{\mathrm{e}}=\kappa-L \sigma T$, where the Lorenz number was calculated from $L=\left(\frac{k_{b}}{e}\right)^{2} \frac{3 F_{0}(\eta) F_{2}(\eta)-4 F_{1}^{2}(\eta)}{F_{0}(\eta)^{2}}$ using the chemical potential of the samples (eq. 1). The calculated $L$ values decrease with increasing temperature for all the samples. The room

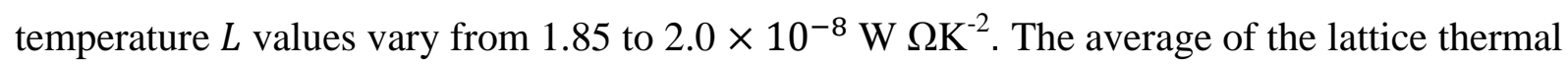
conductivity ( $\kappa_{\text {lat,avg }}$; see Figure $4 d$ ) was calculated in the temperature range where the SPB model is approximately valid [32]; data where the influence of the bipolar thermal conductivity is significant is thus excluded from the averaging. It shows that the IM samples have a higher average lattice thermal conductivity, with the difference decreasing with increasing temperature. This is possibly due to the four times larger grain size of the IM samples which leads to reduced phonon scattering. As $\mathrm{MgO}$ has a higher thermal conductivity than solid solutions of $\mathrm{Mg}_{2} \mathrm{Si}$ and $\mathrm{Mg}_{2} \mathrm{Sn}$, the observed $\mathrm{MgO}$ content in the IM samples (6.64, 9.37, and $7.37 \mathrm{wt} \%$ ) can also be the reason for their higher thermal conductivity in agreement with an estimation in [25]. On the other hand one might expect additional phonon scattering in the IM samples due to a lesser homogeneity and more secondary phases. However, from the obtained results we conclude that this is overcompensated.

The figure of merit $z T$ can be written as $z T=\frac{S^{2}}{L+(\psi \beta)^{-1}}$ with $\psi=\frac{8 \pi e}{3}\left(\frac{2 m_{0} k_{B}}{h^{2}}\right)^{1.5} F_{0}(\eta)$ and the material parameter $\beta=\frac{\left(\frac{m_{D}^{*}}{m_{0}}\right)^{1.5} \mu_{0} T^{2.5}}{\kappa_{\text {lat }}}$ that can be used to evaluate the performance of thermoelectric materials $[65,67,68]$. To calculate $z T$ from the material properties we have used average values for $\mu_{0}, \kappa_{\text {lat }}$ (averaging among the samples) up to $500 \mathrm{~K}$ where the SPB model is approximately valid and $m_{\mathrm{D}}^{*}\left(m_{D}^{*}=1.2 m_{0}\right) . \mu_{0}, \kappa_{\text {lat }}$ were averaged for BM and IM separately and $\mu_{0}$ was obtained directly from the experimental $\mu_{\mathrm{H}}$, not by use of Eq. 5 . Due to the lower mobility of the IM samples and their higher lattice thermal conductivity, they exhibit a significantly reduced $(\approx 20 \%)$ material parameter $\beta$, see Figure 7 a. Note that the SPB model and hence $\beta$ is in principle developed for a homogenous material and not for a material 
with secondary phases. On the other hand, $\beta=\beta\left(\mu_{0}, \kappa_{\text {lat }}\right)$ which both depend the microstructure of a material, even if it is single phase $[69,70]$. Thus, if $\beta$ is obtained from experimental data, it is not a "true" material parameter anymore but an effective one. In the same sense $\beta$ is an effective material parameter here which also includes the effect of secondary phases, in addition to the matrix.
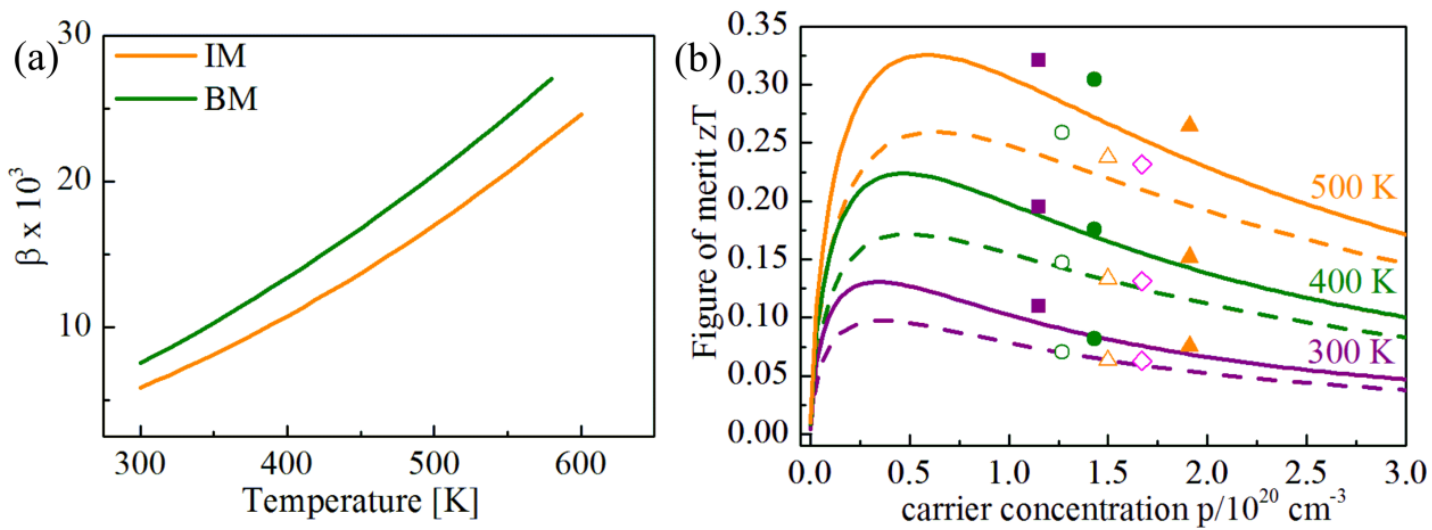

Figure 7(a) Thermoelectric material parameter $\beta$ for BM and IM samples and (b) experimental data (markers) as well as SPB prediction for the figure of merit $z T$ vs carrier concentration of BM samples (solid lines) and IM samples (dashed lines) at 300,400 , and $500 \mathrm{~K}$

The $z T$ predicted by the SPB model is shown in Figure $7 \mathrm{~b}$; for the experimental data we have assumed that $p$ is constant in the temperature range considered. Due to a larger effective parameter $\beta$, the thermoelectric figure of merit is larger for the BM samples at all temperatures, in agreement with the experimental values. The discrepancy between modelling and experimental data at $500 \mathrm{~K}$ might be caused by using the room temperature value of $m_{D}^{*}$ for all temperatures. This might not be perfectly fulfilled as e.g. for n-type $\mathrm{Mg}_{2} \mathrm{Si}$ a small but systematic increase with temperature was observed $[15,35]$. From the experimental data and theoretical calculation, the optimized $z T$ and optimum carrier concentration for the p$\mathrm{Mg}_{2} \mathrm{Si}_{0.2} \mathrm{Sn}_{0.8}$ are achieved for $p \approx 0.5 \times 10^{20} \mathrm{~cm}^{-3}$ at $500 \mathrm{~K}$. Note that the optimum carrier concentration increases with temperature $[32,72]$ and that the SPB tends to overpredict the performance of low doped samples as it neglects the detrimental influence of minority carriers. However, as this effect depends mainly on the band structure it is similar for both IM and BM samples and does not affect the validity of our comparison.

Independent of that the analysis clearly shows that samples synthesized by BM have a superior thermoelectric performance. The ratio of the material parameters $\frac{\beta_{\mathrm{BM}}}{\beta_{\mathrm{IM}}} \approx 1.20$ is significantly larger than unity for all temperatures as is the predicted figure of merit at 
optimum carrier concentration, e.g. $\frac{z T_{\mathrm{opt}, \mathrm{BM}}}{z T_{\mathrm{opt}, \mathrm{IM}}} \approx \frac{0.33}{0.26} \approx 1.27$ at $500 \mathrm{~K}$. To capture the behavior at high temperatures, where the SPB model is not valid anymore it is also insightful to compare $z T_{\text {avg }}$ [71] for samples with similar carrier concentrations. For that comparison we chose the BM sample and the IM with $y=0.02$ as both have similar carrier concentrations, see Table 2. We obtain $\frac{z T_{\text {avg,BM }}}{z T_{\text {avg,IM }}} \approx \frac{0.28}{0.23} \approx 1.22$ confirming the trend observed from the SPB model. Finally, from an application point of view one of the most crucial quantities is the device efficiency. Solving the full heat equation in a finite element approach we obtain a predicted leg efficiency of $4.86 \%$ for a p-leg with the properties of the BM sample, but only $4.25 \%$ for that with the IM properties. We have assumed hot and cold side temperatures of $723 \mathrm{~K}$ and $300 \mathrm{~K}$ respectively, 1D heat and current flow and disregarded electrical and thermal contact resistances, for further details please see the supporting info (Figure S6). Comparing other samples leads to similar results. In summary both the comparison of the material parameters within the framework of the SPB model as well as the predicted performance for individual samples reveal a significant advantage of the BM route compared to the IM route.

\section{Conclusions}

We have successfully synthesized Li-doped $\mathrm{Mg}_{2} \mathrm{Si}_{0.2} \mathrm{Sn}_{0.8}$ by high energy ball milling and induction melting with qualitatively similar thermoelectric properties $\left(z T_{\max } \approx 0.4\right)$. However, the choice of synthesis technique has a clear influence on the microstructure and functional homogeneity of the samples. IM samples have a larger grain size and contain $\mathrm{MgO}$ and Si-rich $\mathrm{Mg}_{2}(\mathrm{Si}, \mathrm{Sn})$ as secondary phases within the matrix. An in-depth analysis of the influence of synthesis technique on the thermoelectric properties has been done using a SPB model. This reveals an increased carrier scattering for IM samples and could indicate that the presence of secondary phases leads to a lower effective mobility, and consequently reduced electrical conductivity. Moreover, the combination of the secondary phases and the larger grain size for the IM samples give rise to a higher lattice thermal conductivity. In summary the low mobility and the high lattice thermal conductivity lead to a significantly reduced effective material parameter $\beta(\approx 20 \%)$ for the IM samples. This results in a significantly lower average figure of merit $\left(\frac{z T_{\mathrm{avg}, \mathrm{BM}}}{z T_{\mathrm{avg}, \mathrm{IM}}} \approx \frac{0.28}{0.23} \approx 1.22\right)$ and thus a clearly poorer performance of the IM samples, even if the maximum figures of merit are comparable. Analysis of the data also shows that the density of states effective mass is independent of the synthesis techniques $\left(m_{\mathrm{D}}^{*} \approx 1.2 \mathrm{~m}_{0}\right)$ and the carrier concentration increases subproportional for both samples with 
slightly higher dopant efficiency for BM samples. In summary, we have demonstrated how the influence of synthesis techniques on microstructure and the thermoelectric properties can be explained well using $\mathrm{p}-\mathrm{Mg}_{2} \mathrm{Si}_{0.2} \mathrm{Sn}_{0.8}$ as an example. The analysis of the transport data in a SPB model is a powerful tool to evaluate different synthesis techniques and understand and quantify the fundamental differences between those.

\section{Acknowledgements}

We would like to gratefully acknowledge the endorsement from the DLR Executive Board Member for Space Research and Technology and the financial support from the Young Research Group Leader Program. The authors would like to thank to P. Blaschkewitz (DLR) for his untiring support with the thermoelectric measurements. The authors (H.K. and A.S.) would like to acknowledge financial support by the DAAD (Fellowships no. 247). The authors (H.K., G.K., T. D. and J.d.B.) would like to acknowledge financial support by the DAAD-DST collaboration (Project ID: 57317956). Also, financial support of one of the authors (J.d.B.) is partially funded by the Deutsche Forschungsgemeinschaft (DFG, German Research Foundation) - project number 396709363.

\section{References}

[1] D. Champier, Thermoelectric generators: A review of applications, Energy Conversion and Management 140 (2017) 167181.

[2] L.E. Bell, Cooling, heating, generating power, and recovering waste heat with thermoelectric systems, Science 321(5895) (2008) 1457-1461.

[3] X. Hu, P. Jood, M. Ohta, M. Kunii, K. Nagase, H. Nishiate, M.G. Kanatzidis, A. Yamamoto, Power generation from nanostructured PbTe-based thermoelectrics: comprehensive development from materials to modules, Energy \& Environmental Science 9(2) (2016) 517-529.

[4] Y. Qiu, L. Xi, X. Shi, P. Qiu, W. Zhang, L. Chen, J.R. Salvaor, J.Y. Cho, J. Yang, Y.C. Chien, S.W. Chen, Y. Tang, G.J. Snyder, Charge-Compensated Compound Defects in Ga-containing Thermoelectric Skutterudites, Advanced Functional Materials 23(25) (2013) 3194-3203.

[5] X. Yan, G. Joshi, W. Liu, Y. Lan, H. Wang, S. Lee, J.W. Simonson, S.J. Poon, T.M. Tritt, G. Chen, Z.F. Ren, Enhanced Thermoelectric Figure of Merit of p-Type Half-Heuslers, Nano Letters 11(2) (2011) 556-560.

[6] C. Hu, K. Xia, X. Chen, X. Zhao, T. Zhu, Transport mechanisms and property optimization of p-type (Zr, Hf)CoSb halfHeusler thermoelectric materials, Materials Today Physics 7 (2018) 69-76.

[7] J. Zhang, L. Song, S.H. Pedersen, H. Yin, L.T. Hung, B.B. Iversen, Discovery of high-performance low-cost n-type $\mathrm{Mg}_{3} \mathrm{Sb}_{2}$-based thermoelectric materials with multi-valley conduction bands, Nature Communications 8 (2017) 13901.

[8] W. Liu, X. Tan, K. Yin, H. Liu, X. Tang, J. Shi, Q. Zhang, C. Uher, Convergence of Conduction Bands as a Means of Enhancing Thermoelectric Performance of n-Type $\mathrm{Mg}_{2} \mathrm{Si}_{1-\mathrm{x}} \mathrm{Sn}_{\mathrm{x}}$ Solid Solutions, Physical Review Letters 108(16) (2012) 166601 .

[9] X. Tang, P. Li, S. Deng, Q. Zhang, High temperature thermoelectric transport properties of double-atom-filled clathrate compounds $\mathrm{Yb}_{\mathrm{x}} \mathrm{Ba}_{8-\mathrm{x}} \mathrm{Ga}_{16} \mathrm{Ge}_{30}$, Journal of Applied Physics 104(1) (2008) 013706. 
[10] W. Liu, H. Chi, H. Sun, Q. Zhang, K. Yin, X. Tang, Q. Zhang, C. Uher, Advanced thermoelectrics governed by a single parabolic band: $\mathrm{Mg}_{2} \mathrm{Si}_{0.3} \mathrm{Sn}_{0.7}$, a canonical example, Physical Chemistry Chemical Physics 16(15) (2014) 6893-6897.

[11] W. Liu, X. Tang, H. Li, K. Yin, J. Sharp, X. Zhou, C. Uher, Enhanced thermoelectric properties of n-type $\mathrm{Mg}_{2.16}\left(\mathrm{Si}_{0.4} \mathrm{Sn}_{0.6}\right)_{1-\mathrm{y}} \mathrm{Sb}_{\mathrm{y}}$ due to nano-sized Sn-rich precipitates and an optimized electron concentration, Journal of Materials Chemistry 22(27) (2012) 13653-13661.

[12] Y. Zheng, Q. Zhang, X. Su, H. Xie, S. Shu, T. Chen, G. Tan, Y. Yan, X. Tang, C. Uher, G.J. Snyder, Mechanically Robust BiSbTe Alloys with Superior Thermoelectric Performance: A Case Study of Stable Hierarchical Nanostructured Thermoelectric Materials, Advanced Energy Materials 5(5) (2015) 1401391.

[13] X. Su, F. Fu, Y. Yan, G. Zheng, T. Liang, Q. Zhang, X. Cheng, D. Yang, H. Chi, X. Tang, Q. Zhang, C. Uher, Selfpropagating high-temperature synthesis for compound thermoelectrics and new criterion for combustion processing, Nature Communications 5 (2014) 4908.

[14] A. Sankhla, A. Patil, H. Kamila, M. Yasseri, N. Farahi, E. Mueller, J. de Boor, Mechanical Alloying of Optimized $\mathrm{Mg}_{2}(\mathrm{Si}, \mathrm{Sn})$ Solid Solutions: Understanding Phase Evolution and Tuning Synthesis Parameters for Thermoelectric Applications, ACS Applied Energy Materials 1(2) (2018) 531-542.

[15] S.K. Bux, M.T. Yeung, E.S. Toberer, G.J. Snyder, R.B. Kaner, J.P. Fleurial, Mechanochemical synthesis and thermoelectric properties of high quality magnesium silicide, Journal of Materials Chemistry 21(33) (2011) 12259-12266.

[16] X. Zhang, Q.M. Lu, L. Wang, F.P. Zhang, J.X. Zhang, Preparation of $\mathrm{Mg}_{2} \mathrm{Si}_{1-\mathrm{x}} \mathrm{Sn}_{\mathrm{x}}$ by Induction Melting and Spark Plasma Sintering, and Thermoelectric Properties, Journal of Electronic Materials 39(9) (2010) 1413-1417.

[17] R. Biswas, S. Mukherjee, R.C. Mallik, S. Vitta, T. Dasgupta, Ultralow thermal conductivity and low charge carrier scattering potential in $\mathrm{Zn}_{1-\mathrm{x}} \mathrm{Cd}_{\mathrm{x}} \mathrm{Sb}$ solid solutions for thermoelectric application, Materials Today Energy 12 (2019) 107-113.

[18] K. Mitra, G.K. Goyal, E. Rathore, K. Biswas, S. Vitta, S. Mahapatra, T. Dasgupta, Enhanced Thermoelectric Performance in $\mathrm{Mg}_{2} \mathrm{Si}$ by Functionalized Co-Doping, physica status solidi (a) 0(0) 1700829.

[19] L.D. Zhao, B.P. Zhang, J.F. Li, H.L. Zhang, W.S. Liu, Enhanced thermoelectric and mechanical properties in textured ntype $\mathrm{Bi}_{2} \mathrm{Te}_{3}$ prepared by spark plasma sintering, Solid State Sciences 10(5) (2008) 651-658.

[20] C. Yu, T.J. Zhu, R.Z. Shi, Y. Zhang, X.B. Zhao, J. He, High-performance half-Heusler thermoelectric materials Hf ${ }_{1-x}$ $\mathrm{Zr}_{\mathrm{x}} \mathrm{NiSn}_{1-\mathrm{y}} \mathrm{Sb}_{\mathrm{y}}$ prepared by levitation melting and spark plasma sintering, Acta Materialia 57(9) (2009) 2757-2764.

[21] L.D. Zhao, B.P. Zhang, J.F. Li, M. Zhou, W.S. Liu, J. Liu, Thermoelectric and mechanical properties of nano-SiCdispersed $\mathrm{Bi}_{2} \mathrm{Te}_{3}$ fabricated by mechanical alloying and spark plasma sintering, Journal of Alloys and Compounds 455(1) (2008) 259-264.

[22] S. LeBlanc, S.K. Yee, M.L. Scullin, C. Dames, K.E. Goodson, Material and manufacturing cost considerations for thermoelectrics, Renewable and Sustainable Energy Reviews 32 (2014) 313-327.

[23] M.W. Gaultois, T.D. Sparks, C.K.H. Borg, R. K. Seshadri, W.D. Bonificio, D.R. Clarke, Data-Driven Review of Thermoelectric Materials: Performance and Resource Considerations, Chemistry of Materials 25(15) (2013) 2911-2920.

[24] J. de Boor, T. Dasgupta, E. Mueller, Thermoelectric Properties of Magnesium Silicide Based Solid Solution and Higher Manganese Silicides, in : C. Uher (Ed.) Materials aspect of thermoelectricity, CRC press Taylor \& Francis2016.

[25] P. Gao, J.D. Davis, V.V. Poltavets, T.P. Hogan, The p-type $\mathrm{Mg}_{2} \mathrm{Li}_{\mathrm{x}} \mathrm{Si}_{0.4} \mathrm{Sn}_{0.6}$ thermoelectric materials synthesized by a $\mathrm{B}_{2} \mathrm{O}_{3}$ encapsulation method using $\mathrm{Li}_{2} \mathrm{CO}_{3}$ as the doping agent, Journal of Materials Chemistry C 4(5) (2016) 929-934.

[26] W. Liu, K. Yin, X. Su, H. Li, Y. Yan, X. Tang, C. Uher, Enhanced hole concentration through Ga doping and excess of $\mathrm{Mg}$ and thermoelectric properties of p-type $\mathrm{Mg}_{2(1+z)}\left(\mathrm{Si}_{0.3} \mathrm{Sn}_{0.7}\right)_{1-\mathrm{y}} \mathrm{Ga}_{\mathrm{y}}$, Intermetallics 32 (2013) 352-361.

[27] Q. Zhang, L. Cheng, W. Liu, Y. Zheng, X. Su, H. Chi, H. Liu, Y. Yan, X. Tang, C. Uher, Low effective mass and carrier concentration optimization for high performance p-type $\mathrm{Mg}_{2(1-\mathrm{x})} \mathrm{Li}_{2 \mathrm{x}} \mathrm{Si}_{0.3} \mathrm{Sn}_{0.7}$ solid solutions, Physical Chemistry Chemical Physics 16(43) (2014) 23576-23583.

[28] G.N. Isachenko, A.Y. Samunin, E.A. Gurieva, M.I. Fedorov, D.A. Pshenay-Severin, P.P. Konstantinov, M.D. Kamolova, Thermoelectric Properties of Nanostructured $\mathrm{p}-\mathrm{Mg}_{2} \mathrm{Si}_{\mathrm{x}} \mathrm{Sn}_{1-\mathrm{x}}(\mathrm{x}=0.2$ to 0.4) Solid Solutions, Journal of Electronic Materials 45(3) (2016) 1982-1986. 
[29] X. Tang, G. Wang, Y. Zheng, Y. Zhang, K. Peng, L. Guo, S. Wang, M. Zeng, J. Dai, G. Wang, X. Zhou, Ultra rapid fabrication of p-type Li-doped $\mathrm{Mg}_{2} \mathrm{Si}_{0.4} \mathrm{Sn}_{0.6}$ synthesized by unique melt spinning method, Scripta Materialia 115 (2016) 52 56.

[30] J. de Boor, U. Saparamadu, J. Mao, K. Dahal, E. Mueller, Z. Ren, Thermoelectric performance of Li doped, p-type $\mathrm{Mg}_{2}(\mathrm{Ge}, \mathrm{Sn})$ and comparison with $\mathrm{Mg}_{2}(\mathrm{Si}, \mathrm{Sn})$, Acta Materialia 120 (2016) 273-280.

[31] J. de Boor, S. Gupta, H. Kolb, T. Dasgupta, E. Mueller, Thermoelectric transport and microstructure of optimized $\mathrm{Mg}_{2} \mathrm{Si}_{0.8} \mathrm{Sn}_{0.2}$, Journal of Materials Chemistry C 3(40) (2015) 10467-10475.

[32] H. Kamila, P. Sahu, A. Sankhla, M. Yasseri, H.N. Pham, T. Dasgupta, E. Mueller, J. de Boor, Analyzing transport properties of p-type $\mathrm{Mg}_{2} \mathrm{Si}-\mathrm{Mg}_{2} \mathrm{Sn}$ solid solutions: optimization of thermoelectric performance and insight into the electronic band structure, Journal of Materials Chemistry A 7(3) (2019) 1045-1054.

[33] X. Tang, Y. Zhang, Y. Zheng, K. Peng, T. Huang, X. Lu, G. Wang, S. Wang, X. Zhou, Improving thermoelectric performance of p-type Ag-doped $\mathrm{Mg}_{2} \mathrm{Si}_{0.4} \mathrm{Sn}_{0.6}$ prepared by unique melt spinning method, Applied Thermal Engineering 111 (2017) 1396-1400.

[34] U. Saparamadu, J. de Boor, J. Mao, S. Song, F. Tian, W. Liu, Q. Zhang, Z. Ren, Comparative studies on thermoelectric properties of p-type $\mathrm{Mg}_{2} \mathrm{Sn}_{0.75} \mathrm{Ge}_{0.25}$ doped with lithium, sodium, and gallium, Acta Materialia 141 (2017) 154-162.

[35] J. de Boor, T. Dasgupta, H. Kolb, C. Compere, K. Kelm, E. Mueller, Microstructural effects on thermoelectric efficiency: A case study on magnesium silicide, Acta Materialia 77 (2014) 68-75.

[36] G.S. Polymeris, N. Vlachos, A.U. Khan, E. Hatzikraniotis, C.B. Lioutas, A. Delimitis, E. Pavlidou, K.M. Paraskevopoulos, T. Kyratsi, Nanostructure and doping stimulated phase separation in high-ZT $\mathrm{Mg}_{2} \mathrm{Si}_{0.55} \mathrm{Sn}_{0.4} \mathrm{Ge}_{0.05}$ compounds, Acta Materialia 83 (2015) 285-293.

[37] P. Bellanger, S. Gorsse, G. Bernard-Granger, C. Navone, A. Redjaimia, S. Vivès, Effect of microstructure on the thermal conductivity of nanostructured $\mathrm{Mg}_{2}(\mathrm{Si}, \mathrm{Sn})$ thermoelectric alloys: An experimental and modeling approach, Acta Materialia 95 (2015) 102-110.

[38] X. Liu, L. Xi, W. Qiu , J.Yang, T. Zhu, X. Zhao, W. Zhang, Significant Roles of Intrinsic Point Defects in $\mathrm{Mg}_{2} \mathrm{X}(\mathrm{X}=$ $\mathrm{Si}, \mathrm{Ge}, \mathrm{Sn})$ Thermoelectric Materials, Advanced Electronic Materials 2(2) (2016) 1500284.

[39] T. Dasgupta, C. Stiewe, J. de Boor, E. Mueller, Influence of power factor enhancement on the thermoelectric figure of merit in $\mathrm{Mg}_{2} \mathrm{Si}_{0.4} \mathrm{Sn}_{0.6}$ based materials, physica status solidi (a) 211(6) (2014) 1250-1254.

[40] G.J. Snyder, E.S. Toberer, Complex thermoelectric materials, Nature Materials 7 (2008) 105.

[41] H.S. Wang, S.Q. Bai, L.D. Chen, A. Cuenat, G. Joshi, H. Kleinke, J. König, H.W. Lee, J. Martin, M.W. Oh, W.D. Porter, Z.Ren, J. Salvador, J. Sharp, P. Taylor, A.J. Thompson, Y.C. Tseng, International Round-Robin Study of the Thermoelectric Transport Properties of an n-Type Half-Heusler Compoundfrom $300 \mathrm{~K}$ to $773 \mathrm{~K}$, Journal of Electronic Materials 44(11) (2015) 4482-4491.

[42] H. Kamila, A. Sankhla, M. Yasseri, N.P. Hoang, N. Farahi, E. Mueller, J. de Boor, Synthesis of p-type $\operatorname{Mg}_{2} \operatorname{Si}_{1-x} \operatorname{Sn}_{x}$ with $\mathrm{x}=0-1$ and optimization of the synthesis parameters, Materials Today: Proceedings 8 (2019) 546-555.

[43] J. de Boor, T. Dasgupta, U. Saparamadu, E. Mueller, Z. Ren, Recent progress in p-type thermoelectric magnesium silicide based solid solutions, Materials Today Energy 4 (2017) 105-121.

[44] S. Vivès, P. Bellanger, S. Gorsse, C. Wei, Q. Zhang, J.C. Zhao, Combinatorial approach based on interdiffusion experiments for the design of thermoelectrics: Application to the $\mathrm{Mg}_{2}(\mathrm{Si}, \mathrm{Sn})$ alloys, Chemistry of Materials 26(15) (2014) 4334-4337.

[45] M. Yasseri, N. Farahi, K. Kelm, E. Mueller, J. de Boor, Rapid determination of local composition in quasi-binary, inhomogeneous material systems from backscattered electron image contrast, Materialia 2 (2018) 98-103.

[46] D. Boudemagh, D. Fruchart, R. Haettel, E.K. Hlil, A. Lacoste, L. Ortega, N. Skryabina, J. Toboła, P. Wolfers, Crystal structure analysis of the $\mathrm{Mg}_{2} \mathrm{Si}_{1-\mathrm{x}} \mathrm{Sn}_{\mathrm{x}}$ system having potential thermoelectric properties at high temperature, Solid State Phenomena, Trans Tech Publ, 2011, pp. 253-258.

[47] P. Ziolkowski, G. Karpinski, T. Dasgupta, E. Mueller, Probing thermopower on the microscale, physica status solidi (a) 210(1) (2013) 89-105. 
[48] D. Platzek, G. Karpinski, C. Stiewe, P. Ziolkowski, C. Drasar, E. Mueller, Potential-Seebeck-microprobe (PSM): measuring the spatial resolution of the Seebeck coefficient and the electric potential, ICT 2005. 24th International Conference on Thermoelectrics, (2005), pp. 13-16.

[49] J. de Boor, E. Mueller, Data analysis for Seebeck coefficient measurements, Review of Scientific Instruments 84(6) (2013) 065102.

[50] J. de Boor, C. Stiewe, P. Ziolkowski, T. Dasgupta, G. Karpinski, E. Lenz, F. Edler, E. Mueller, High-Temperature Measurement of Seebeck Coefficient and Electrical Conductivity, Journal of Electronic Materials 42(7) (2013) 1711-1718.

[51] K.A. Borup, J. de Boor, H. Wang, F. Drymiotis, F. Gascoin, X. Shi, L. Chen, M.I. Fedorov, E. Mueller, B.B. Iversen, G.J. Snyder, Measuring thermoelectric transport properties of materials, Energy \& Environmental Science 8(2) (2015) 423435 .

[52] G.N. Lewis, The Specific Heat of solids at constant volume and the law of Dulong Petit, Journal of the American Chemical Society 29(8) (1907) 1165-1168.

[53] L.J.van der Pauw, A method of measuring specific resistivity and Hall effect of discs of arbitrary shape, Philips Res. Rep 13(1) (1958) 1-9.

[54] J. Martin, Apparatus for the high temperature measurement of the Seebeck coefficient in thermoelectric materials, Review of Scientific Instruments 83(6) (2012) 065101.

[55] P. Ziolkowski, C. Stiewe, J. de Boor, I. Druschke, K. Zabrocki, F. Edler, S. Haupt, J. König, E. Mueller, Iron Disilicide as High-Temperature Reference Material for Traceable Measurements of Seebeck Coefficient Between $300 \mathrm{~K}$ and $800 \mathrm{~K}$, Journal of Electronic Materials 46(1) (2017) 51-63.

[56] M. Søndergaard, M. Christensen, K.A. Borup, H. Yin, B.B. Iversen, Thermoelectric Properties of the Entire Composition Range in $\mathrm{Mg}_{2} \mathrm{Si}_{0.9925-} \mathrm{Sn}_{\mathrm{x}} \mathrm{Sb}_{0.0075}$, Journal of electronic materials 42(7) (2013) 1417-1421.

[57] W. Luo, M. Yang, F. Chen, Q. Shen, H. Jiang, L. Zhang, Fabrication and thermoelectric properties of $\operatorname{Mg}_{2} \operatorname{Si}_{1-x} \operatorname{Sn}_{\mathrm{x}}$ $(0 \leq x \leq 1.0)$ solid solutions by solid state reaction and spark plasma sintering, Materials Science and Engineering: B 157(1) (2009) 96-100.

[58] Q. Zhang, T.J. Zhu, A.J. Zhou, H. Yin, X.B. Zhao, Preparation and thermoelectric properties of $\operatorname{Mg}_{2} \operatorname{Si}_{1-x} \operatorname{Sn}_{x}, P$ hysica Scripta T129 (2007) 123-126.

[59] G. Skomedal, A. Burkov, A. Samunin, R. Haugsrud, H. Middleton, High temperature oxidation of $\mathrm{Mg}_{2}(\mathrm{Si}-\mathrm{Sn})$, Corrosion Science 111 (2016) 325-333.

[60] S. Vivès, P. Bellanger, S. Gorsse, C. Wei, Q. Zhang, J.C. Zhao, Combinatorial Approach Based on Interdiffusion Experiments for the Design of Thermoelectrics: Application to the $\mathrm{Mg}_{2}(\mathrm{Si}, \mathrm{Sn})$ Alloys, Chemistry of Materials 26(15) (2014) 4334-4337.

[61] J. Harrison, J. Hauser, Alloy scattering in ternary III-V compounds, Physical Review B 13(12) (1976) 5347.

[62] H. Wang, A.D. Lalonde, Y. Pei, G.J. Snyder, The Criteria for Beneficial Disorder in Thermoelectric Solid Solutions, Advanced Functional Materials 23(12) (2013) 1586-1596.

[63] J. Bardeen, W. Shockley, Deformation Potentials and Mobilities in Non-Polar Crystals, Physical Review 80(1) (1950) $72-80$.

[64] J.Y.W. Seto, The electrical properties of polycrystalline silicon films, Journal of Applied Physics 46(12) (1975) 52475254.

[65] V.I. Fistul, Heavily doped semiconductors, Springer Science \& Business Media2012.

[66] J.J. Kuo, S.D. Kang, K. Imasato, H. Tamaki, S. Ohno, T. Kanno, G.J. Snyder, Grain boundary dominated charge transport in $\mathrm{Mg}_{3} \mathrm{Sb}_{2}$-based compounds, Energy \& Environmental Science 11(2) (2018) 429-434.

[67] A.F. May, High-temperature transport in lanthanum telluride and other modern thermoelectric materials, California Institute of Technology (2010).

[68] A.F. May, G.J. Snyder, Introduction to modeling thermoelectric transport at high temperatures, Materials, preparation, and characterization in thermoelectrics. CRC Press, Boca Raton 11 (2012). 
[69] K. Zhao, P. Qiu, Q. Song, A.B. Blichfeld, E. Eikeland, D. Ren, B. Ge, B.B. Iversen, X. Shi, L. Chen, Ultrahigh thermoelectric performance in $\mathrm{Cu}_{2-\mathrm{y}} \mathrm{Se}_{0.5} \mathrm{~S}_{0.5}$ liquid-like materials, Materials Today Physics 1 (2017) 14-23.

[70] J. Lei, D. Zhang, W. Guan, Z. Ma, Z. Cheng, C. Wang, Y. Wang, Enhancement of thermoelectric figure of merit by the insertion of multi-walled carbon nanotubes in $\alpha-\mathrm{MgAgSb}$, Applied Physics Letters 113(8) (2018) 083901.

[71] F. Ioffe, Semiconductor Thermoelements and Thermoelectric Refrigeration, Infosearch, London (1957) 39.

[72] T. Zhu, Y. Liu, C. Fu, J.P. Heremans, J.G. Snyder, X. Zhao, Compromise and Synergy in High-Efficiency Thermoelectric Materials Advanced Materials (2017) 1605884-n/a. 